\title{
Remediation of Mariculture Sediment by Sediment Microbial Fuel Cell
}

\author{
Nannan Zhao ${ }^{1, *}$ \\ ${ }^{1}$ College of Environmental Science and Engineering, Ocean University of China, Qingdao, China
}

\begin{abstract}
To investigate the removal effect of pollutants in mariculture sediment by sediment microbial fuel cell (SMFC) and its power generation capacity, the effects of external resistance, cathode $\mathrm{pH}$ and cathode dissolved oxygen concentration (DO) on the SMFC system were investigated. The results showed that the optimal parameters for SMFC were as follows: external resistance $=1500 \Omega, \mathrm{pH}=8.5$ and $\mathrm{DO}=5 \mathrm{mg} \cdot \mathrm{L}^{-1}$. In these situations, the power generation performance and organic degradation effect were both the best. The maximum output voltages were 585,606 , and $587 \mathrm{mV}$, respectively; the removal rates of COD in sediment were $75.51 \%, 84.21 \%$ and $86.63 \%$, respectively; and the removal rates of ammonia nitrogen in sediment were $80.34 \%, 98.91 \%$ and $90.24 \%$, respectively. The SMFC system had a certain degradation ability to pollutants such as COD and ammonia nitrogen in the sediment of the marine aquaculture areas, which had a broad application prospect.
\end{abstract}

\section{Introduction}

Sediment is not only an important part of the aquaculture water body in the mariculture area, but also a natural storage reservoir, which is a "sink" including various pollutants and nutrients. In addition, the sediment in the mariculture areas can be used as an internal source of pollution, releasing pollutants into the overlying seawater, which not only interferes with water quality restoration, but also accelerates water pollution ${ }^{[1]}$. Therefore, it is necessary to control the pollutants of the sediment in the mariculture areas while reducing the pollution of the overlying seawater.

Sediment microbial fuel cell (SMFC) is a type of microbial fuel cell (MFC), which can convert chemical energy in organic waste into electrical energy while degrading pollutants ${ }^{[2]}$. Electrons in the bioelectrochemical process are generated by electrochemically active bacteria on the anode (buried in anaerobic sediment) to oxidize organic matter, and migrate to the cathode (suspended in aerobic overlying water), and eventually react with oxygen and protons in the water to form water ${ }^{[3,4]}$. Compared with electrolytic cells and traditional biological treatment methods, SMFC is affected by many aspects in the process of using microorganisms to generate electricity and control pollution: modification of electrode materials, optimization of system operating conditions, changes in microbial community structure, types and properties of sediment, pretreatment methods of sediment, etc, which the operating conditions are more important.

In this study, the SMFC system was constructed by sediment from marine aquaculture areas as fuel, the three factors of external resistance, cathode $\mathrm{pH}$ and cathode dissolved oxygen concentration were studied to improve the power generation performance and the pollutant removal effect in the sediment of the aquaculture areas, and provided a theoretical reference for the practical application of the SMFC system in the bioremediation of sediment.

\section{Materials and methods}

\subsection{Sample collection}

The sediment was collected from the marine aquaculture base of Shandong Provincial Institute of Marine Biology. Collected fresh aquaculture seawater at the same location. The samples were stored in a refrigerator at $4^{\circ} \mathrm{C}$ for later use.

\subsection{Construction and operation of SMFC system}

The reaction vessel was a $1 \mathrm{~L}$ beaker, and the thickness of the bottom sediment and the overlying seawater were both $5 \mathrm{~cm}$. Both cathode and anode were made of carbon felt, with a diameter of $6 \mathrm{~cm}$ and a thickness of $0.5 \mathrm{~cm}$. The anode was buried in the sediment, $2 \mathrm{~cm}$ from the bottom of the reactor, the cathode was floating on the water, and the distance between the anode and the cathode was 7.5 $\mathrm{cm}$. The corrosion-resistant titanium wire was selected as the wire, the diameter was $0.5 \mathrm{~mm}$, and the external resistance of the cathode and anode was $1500 \Omega$. The device operated in dark conditions throughout the entire process.

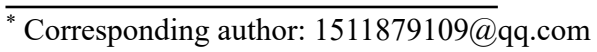




\subsection{Analysis items and methods}

Used a multimeter to collect the SMFC voltage. The polarization curve of the SMFC was measured by the steady-state discharge method, and the resistance value of the resistance box was changed so that the external resistance value was continuously reduced in the range of $10000 \Omega$ to $100 \Omega$. The power density was calculated according to the standard method ${ }^{[5]}$. The measurement methods of the water sample index in the experiment were referred to the standard method stipulated by the country.

\section{Results and discussion}

\subsection{The influence of different external resistance}

In order to select the appropriate value of external resistance, three levels of external resistance $(100,750$ and $1500 \Omega$ ) were examined. Figure 1 is the voltage change curve under different external resistance conditions. It can be clearly seen that the larger the external resistance value, the greater the voltage generated ${ }^{[6]}$, when the external resistance value was $1500 \Omega$, the maximum voltage was $585 \mathrm{mV}$, the maximum voltage at $750 \Omega$ was $192 \mathrm{mV}$, and the maximum voltage at $100 \Omega$ was only $92 \mathrm{mV}$; the maximum voltage with an external resistance of $1500 \Omega$ was 6.36 times than that of $100 \Omega$. This was similar to the research results of Hong [7], the SMFC system was constructed with external resistances of 10,100 , and 1000 $\Omega$, and it was found that the power generation performance was the best under the external resistance of $1000 \Omega$. Since the power is equal to the square of the current multiplied by the external resistance, the output power can be increased by increasing the current or external resistance. Therefore, the SMFC can operate at a higher external resistance to increase power output.

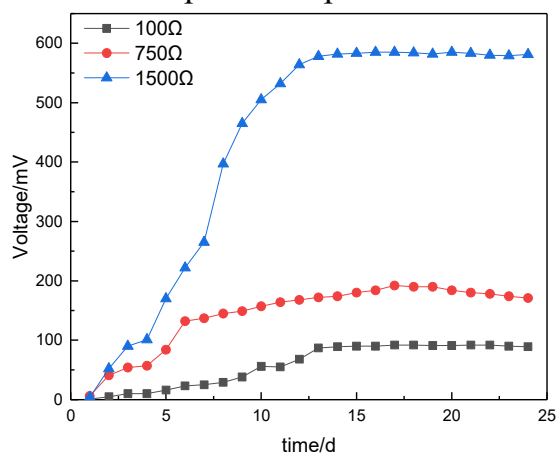

Fig. 1. Voltage changes under different external resistance conditions

Figure 2 and 3 show the COD and ammonia nitrogen content changes of the SMFC system in the sediment with time under three groups of different external resistance conditions. It can be seen that the COD content of each device decreased with the extension of the operating time. The COD removal rate of the 100,750 , and $1500 \Omega$ devices were $57.31 \%, 70.42 \%$ and $75.51 \%$, respectively. Among them, the $1500 \Omega$ device had the highest removal rate of COD, which was 1.32 times than the removal rate of the $100 \Omega$ device. The change trend of ammonia nitrogen in the sediment was the same as that of COD. As the operating time increased, the ammonia nitrogen content in each device decreased significantly. At the beginning of the experiment, the content of ammonia nitrogen in the sediment was $20.6 \mathrm{mg} \cdot \mathrm{kg}^{-1}$. At the end of the experiment, the content of ammonia nitrogen in the sediment of the 100,750 , and $1500 \Omega$ devices dropped to $4.88,5.33$, and $4.03 \mathrm{mg} \cdot \mathrm{kg}^{-1}$, respectively, and the removal rates were $76.19 \%, 73.15 \%$ and $80.34 \%$, respectively, which the $1500 \Omega$ device had the highest removal rate of ammonia nitrogen and the best degradation effect.

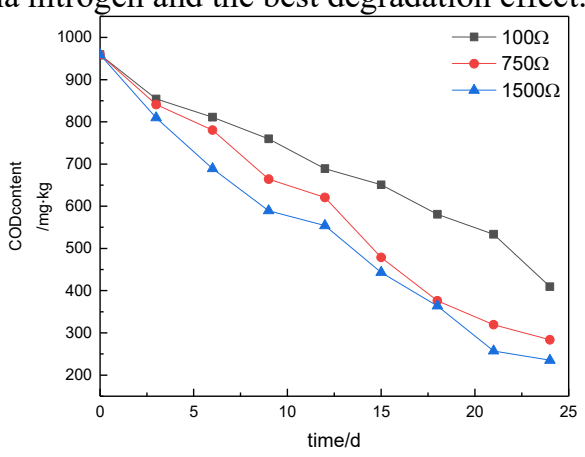

Fig. 2. The content changes of COD with different external resistance conditions

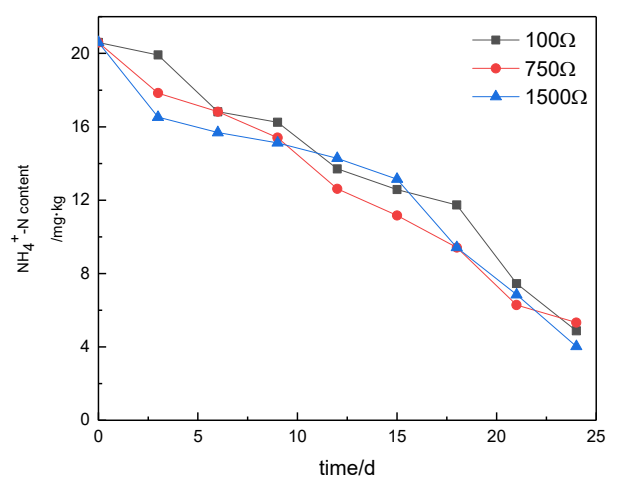

Fig. 3. The content changes of ammonia nitrogen with different external resistance conditions

In summary, when the external resistance was $1500 \Omega$, the SMFC system not only had the highest power generation performance, but also had the best removal effect of organic pollutants in sediment. The power generation performance is proportional to the pollutant removal effect. In proportion, the higher the electricity generation performance, the better the removal of organic matter ${ }^{[6]}$. Therefore, the follow-up experiment selected $1500 \Omega$ for the experiment.

\subsection{The influence of cathode solution $\mathrm{pH}$}

In order to select the appropriate value of $\mathrm{pH}$, three levels of $\mathrm{pH}(6.5,7.5$ and 8.5$)$ were examined. Figure 4 shows the voltage change curve under different $\mathrm{pH}$ conditions. As the operating time increased, the voltage under different $\mathrm{pH}$ conditions also increased. Among them, the maximum voltages generated by $\mathrm{pH} 7.5$ and 8.5 were 597 $\mathrm{mV}$ and $606 \mathrm{mV}$, respectively, which were far greater than the maximum voltage of $\mathrm{pH} 6.5(24 \mathrm{mV})$. In addition, the 
device with a $\mathrm{pH}$ of 8.5 had the shortest start-up time, and the voltage reached a stable value around the 12th day, while the device with a $\mathrm{pH}$ of 7.5 only started after 15 days. Combining the results of output voltage, the device with $\mathrm{pH}$ at 8.5 had the best power generation performance, followed by the $\mathrm{pH} 7.5$ device.

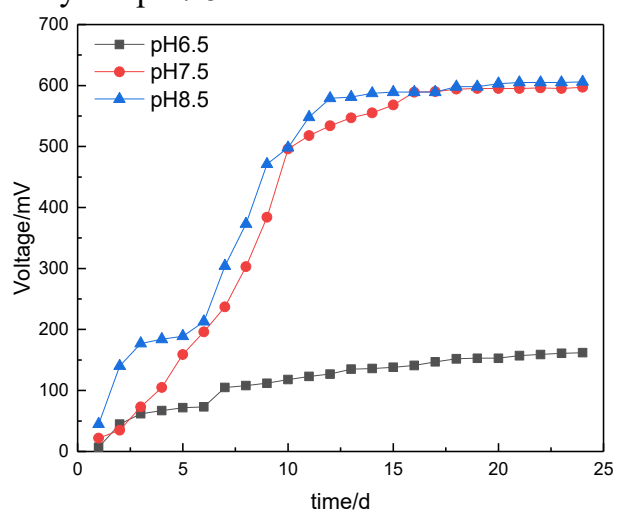

Fig. 4. Voltage changes under different $\mathrm{pH}$ conditions

Figure 5 and 6 show the content changes of COD and ammonia nitrogen in the sediment of different $\mathrm{pH}$ devices with time. The COD content of each device decreased with the extension of running time. At the beginning of the experiment, the COD content in the sediment was $1121.31 \mathrm{mg} \cdot \mathrm{kg}^{-1}$, at the end of the experiment, the COD content in the $\mathrm{pH} 6.5,7.5$ and 8.5 devices dropped to $299.96,204.12$ and $177.05 \mathrm{mg} \cdot \mathrm{kg}^{-1}$, respectively, and the removal rate was $73.25 \%, 81.8 \%$ and $84.21 \%$, respectively. Among them, the $\mathrm{pH} 8.5$ device had the highest removal rate of COD and the best degradation effect. The change trend of ammonia nitrogen in the sediment was the same as that of COD. As the operating time increased, the ammonia nitrogen content in each device decreased significantly. At the beginning of the experiment, the content of ammonia nitrogen in the sediment was $20.6 \mathrm{mg} \cdot \mathrm{kg}^{-1}$, and the removal rates of ammonia nitrogen in the sediment with the $\mathrm{pH} 6.5,7.5$ and 8.5 devices were $93.51 \%, 95.65 \%$ and $98.91 \%$, respectively. Among them, the device with $\mathrm{pH} 8.5$ had the highest removal rate of ammonia nitrogen and the best degradation effect. Behera ${ }^{[8]}$ reported that as the $\mathrm{pH}$ of the influent water decrease, the COD removal rate and electricity production decrease; this result was similar to the results of this study.

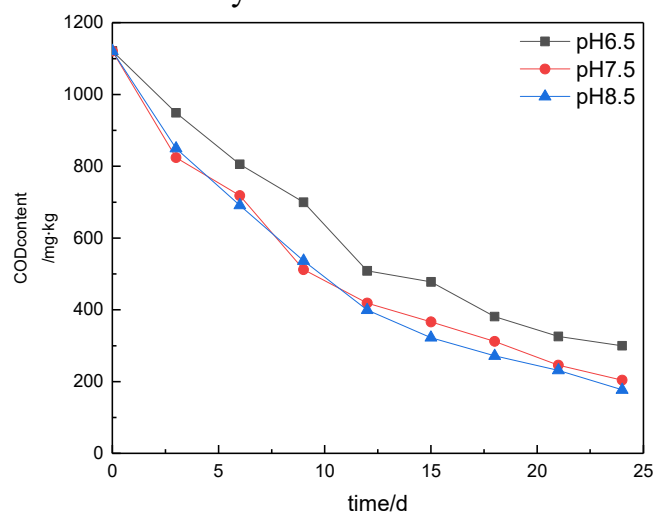

Fig. 5. The content changes of COD with different $\mathrm{pH}$ conditions

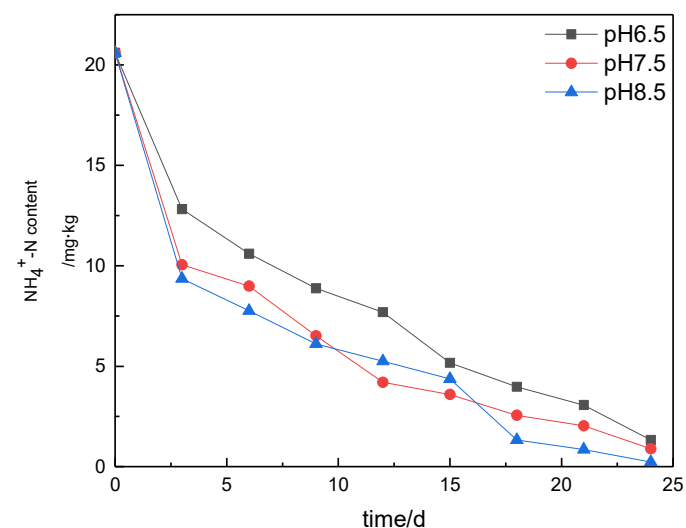

Fig. 6. The content changes of ammonia nitrogen with different $\mathrm{pH}$ conditions

Integrating the SMFC system's power generation performance and organic removal effect, it was found that the $\mathrm{pH}$ of 8.5 was the most appropriate, so the cathode solution $\mathrm{pH}$ was 8.5 for subsequent experiments.

\subsection{The influence of cathode dissolved oxygen concentration}

In order to select the appropriate value of DO, three levels of DO $\left(3,5\right.$ and $\left.7 \mathrm{mg} \cdot \mathrm{L}^{-1}\right)$ were examined. Figure 7 shows the voltage change curve under different dissolved oxygen conditions. As the operating time increased, the voltage under different DO conditions also increased. The maximum voltages with DO of 3,5 , and $7 \mathrm{mg} \cdot \mathrm{L}^{-1}$ were 567,587 , and $623 \mathrm{mV}$, respectively. The start-up time of the devices with DO at 5 and $7 \mathrm{mg} \cdot \mathrm{L}^{-1}$ were the shortest, and the voltage reached a stable value around the 13th day. The device with DO of $3 \mathrm{mg} \cdot \mathrm{L}^{-1}$ only started successfully after 17 days. It showed that the device with DO of 5 $\mathrm{mg} \cdot \mathrm{L}^{-1}$ had the best power generation performance. Generally speaking, $\mathrm{O}_{2}$ is used as the electron acceptor for the cathode reaction of the SMFC fuel cell. The output power generated by the SMFC is related to the availability of DO ${ }^{[9]}$. Proper aeration makes the cathode dissolved oxygen concentration greater than the critical value, which can shorten the system start-up time and increase power generation performance.

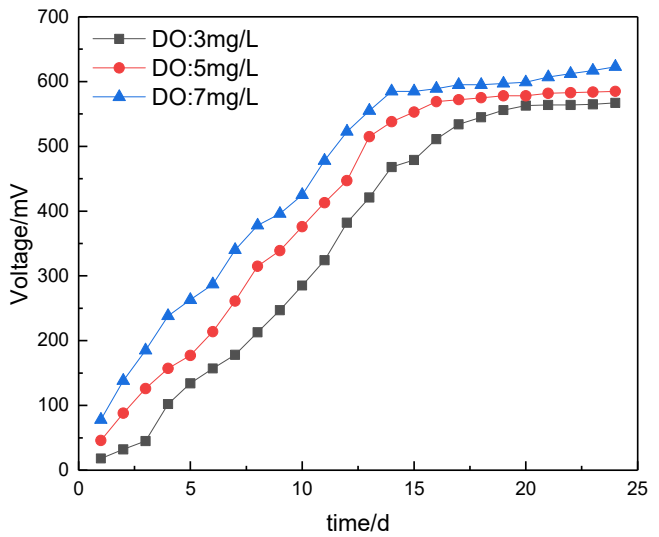

Fig. 7. Voltage changes under different DO conditions

Figure 8 and 9 show the content changes of COD and ammonia nitrogen in the sediment with time under 
different DO conditions. The COD content of each device in the sediment decreased with the extension of operating time. The COD content in the sediment at the beginning of the experiment were all $1125.62 \mathrm{mg} \cdot \mathrm{kg}^{-1}$, and the final the COD content in the DO of 3,5, and $7 \mathrm{mg} \cdot \mathrm{L}^{-1}$ devices decreased to $218.26,150.49$, and $136.49 \mathrm{mg} \cdot \mathrm{kg}^{-1}$, respectively, and the removal rate were $80.61 \%, 86.63 \%$ and $87.83 \%$, respectively. The change trend of ammonia nitrogen in the sediment was the same as that of COD. As the operating time increased, the ammonia nitrogen content in each device decreased significantly. At the beginning of the experiment, the content of ammonia nitrogen in the sediment was $20.51 \mathrm{mg} \cdot \mathrm{kg}^{-1}$, and at the end, the removal rate of ammonia nitrogen in the sediment by the device with a DO of 3,5 and $7 \mathrm{mg} \cdot \mathrm{L}^{-1}$ were $81.61 \%$, $90.24 \%$ and $88 \%$, respectively. Among them, the device with a DO of $5 \mathrm{mg} \cdot \mathrm{L}^{-1}$ had the highest removal rate of ammonia nitrogen and the best degradation effect. Although the increase in the concentration of dissolved oxygen at the cathode will accelerate the oxidationreduction rate of organic matter, over-aeration will increase the energy of the system and increase the operating cost. Therefore, this study used low-intensity aeration to make the concentration of dissolved oxygen at the cathode $5 \mathrm{mg} \cdot \mathrm{L}^{-1}$.

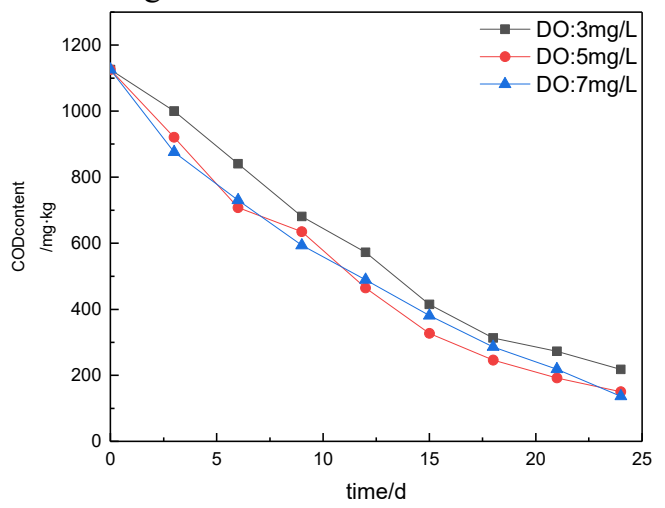

Fig. 8. The content changes of COD with different DO conditions

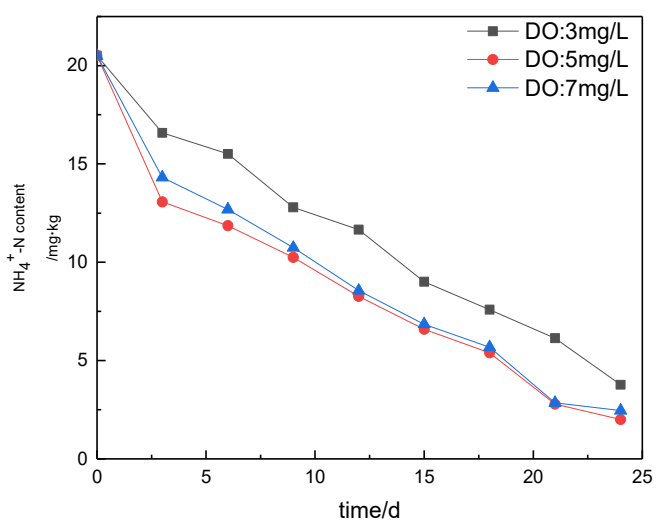

Fig. 9. The content changes of ammonia nitrogen with different DO conditions

Sufficient DO concentration can increase the reduction reaction rate of the cathode and the cathode potential, thereby improving electricity generation performance and pollutant removal. In addition, the output voltage in SMFC is determined by the potential difference between the anode and the cathode. Aeration on the cathode can increase the potential difference and increase the output voltage of the system ${ }^{[10]}$. Based on the SMFC system's power generation performance and the removal of organic matter, it was found that $\mathrm{DO}$ of $5 \mathrm{mg} \cdot \mathrm{L}^{-1}$ was the most appropriate. Therefore, the cathode solution DO concentration of $5 \mathrm{mg} \cdot \mathrm{L}^{-1}$ was selected for experiments.

\section{Conclusion}

Different external resistances had different effects on SMFC. The larger the external resistance, the higher the maximum output voltage. When the external resistance was $1500 \Omega$, the maximum output voltage of the system and the removal rate of organic matter were the highest. The electricity-producing bacteria can fully metabolize the organic matter at the anode to effectively transfer electrons.

Keeping the $\mathrm{pH}$ of the overlying water at 8.5 can shorten the start-up time of the SMFC system and improve the power generation performance, and at the same time facilitate the removal of organic matter in the sediment.

Appropriate aeration on the surface of the overlying water to control the dissolved oxygen concentration of the cathode at $5 \mathrm{mg} \cdot \mathrm{L}^{-1}$ can not only shorten the start-up time of the SMFC and increase the power generation performance of the system, but also improve the removal rate of organic matter in the sediment.

\section{References}

1. H.Q. Zhang, Y.G. Jia, K.G. Wang, F. Lu, Appl. Chem. Indu. 49, 750 (2020)

2. P. Deepak, V. B. Gilbert, D. Ludo, V. Karolien, Bioresour. Technol. 101, 1533 (2010)

3. L. Bruce, H. Bert, F. Stefano, A. Peter, V. Willy, R. Korneel, Environ. Sci. Technol. 40, 5181 (2006)

4. G. Palanisamy, H. Jung, T. Sadhasivam, D. Kurkuri, J. Clea. Prod. 221, 598 (2019)

5. Z.H. Liu, X.M. Li, L. Fang, X. Zheng, L. Yang, Chin. Environ. Sci. 32, 268 (2012)

6. Xu X, Sediment microbial fuel cell enhances pollutant removal efficiency and mechanism in water bodies (Institute of Technology, Harbin, 2017)

7. S.W. Hong, I.S. Chang, Y.S. Choi, T.H. Chung, Bioresour. Technol. 100, 3029(2009)

8. M. Behera, M.M. Ghangrekar, Bioresour. Technol. 100, 5114 (2009)

9. S.E. Oh, B. Min, B.E. Logan, Environ. Sci. Technol. 38, 4900 (2004)

10. S. Srikanth, S.V. Mohani, Bioresour. Technol. 119, 241 (2012) 